\title{
Simulation of Atomic Cadmium Spectroscopy in Rare Gas Solids Using Pair Potentials ${ }^{\dagger}$
}

\author{
Brendan Healy and John G. McCaffrey* \\ Department of Chemistry, National University of Ireland, Maynooth, County Kildare, Ireland
}

Received: October 5, 1999; In Final Form: November 17, 1999

\begin{abstract}
Luminescence in the vacuum UV/visible region has been recently recorded for atomic cadmium isolated in the rare gas solids $\mathrm{Ne}, \mathrm{Ar}, \mathrm{Kr}$, and $\mathrm{Xe}$, and because of the availability of diatomic $\mathrm{Cd} \cdot \mathrm{RG}$ and $\mathrm{RG} \cdot \mathrm{RG}$ pair potentials, theoretical calculations are now performed and compared to the recorded luminescence spectra. Calculations were first done for the gas-phase excited-state cluster species $\mathrm{Cd}\left({ }^{1} \mathrm{P}_{1}\right) \cdot \mathrm{RG}_{n}$, where $n$ is the number of rare gas atoms in the cluster. The $\mathrm{Cd} \cdot \mathrm{RG}_{4}, \mathrm{Cd} \cdot \mathrm{RG}_{5}$, and $\mathrm{Cd} \cdot \mathrm{RG}_{6}$ clusters showed energy minima for the $\mathrm{Cd} \mathrm{p}_{z}$ orbital situated at the center of the planar rare gas clusters. With the rare gas distances in the planar clusters fixed at the rare gas dimer bond lengths, the cluster showing the greatest stabilization was the $\mathrm{Cd}$ $\mathrm{RG}_{5}$ species. The cluster calculations were then extended into the solid state for $\mathrm{Cd}$ occupying a single substitutional site of the solid rare gas lattice. Two vibronic modes lead to a preferential interaction between the guest and four rare gas atoms, thereby reducing the excited-state energy and leading to distinct minima. The modes are (a) the "body" mode $\left(\mathrm{Q}_{2}\right)$, which involves the motion of the $\mathrm{Cd}$ atom toward an octahedral interstitial site and (b) the "waist" mode $\left(\mathrm{Q}_{3}\right)$, which involves the in-phase contraction of four rare gas atoms in a single plane toward the $\mathrm{Cd}$ atom. Calculations based on single substitutional site occupancy of $\mathrm{Cd}$ in the rare gases indicate excited state stabilization for the waist mode for all hosts except neon. The body mode exhibits stabilization in $\mathrm{Kr}$ and $\mathrm{Xe}$ only. The pair of singlet emission bands observed in the $\mathrm{Cd} / \mathrm{Kr}$ system is identified as originating from the stabilization of both vibronic modes in the excited state. The lack of stabilization for either mode in $\mathrm{Ne}$, even though singlet emission exists in $\mathrm{Cd} / \mathrm{Ne}$, is indicative that a multivacancy site occupancy is likely here.
\end{abstract}

\section{Introduction}

Much experimental work has been done on the luminescence of $(n \mathrm{~s})^{2}$ metal atoms isolated in rare gas solids, e.g., $\mathrm{Mg},{ }^{1} \mathrm{Zn},{ }^{2}$ $\mathrm{Hg},{ }^{3}$ and $\mathrm{Cd},{ }^{4}$ and with the increasing amount of spectroscopic data becoming available for diatomic metal atom/rare gas atom van der Waals molecules, it is now possible to predict absorption and emission wavelengths. The cadmium spectroscopy results analyzed here involves the $5 s^{2}-5 s^{1} 5 p^{1}$ transition, which is similar to the $\mathrm{Zn} 4 \mathrm{~s}^{2}-4 \mathrm{~s}^{1} 4 \mathrm{p}^{1}$ system for which previous work on both experimental and predicted luminescence already exists. ${ }^{2,5}$ From calculations done on the excited-state $\mathrm{Zn}\left({ }^{1} \mathrm{P}_{1}\right) /$ $\mathrm{RG}(\mathrm{RG}=\mathrm{Ar}, \mathrm{Kr}$, and $\mathrm{Xe})$ matrix systems, it was shown that interactions between the excited-state guest $\mathrm{Zn}$ atom and four host rare gas atoms achieved the energy minima in the solid state. Two vibronic modes lead to such interactions and thereby to distinct energy minima. One mode involves motion of the guest atom from the substitutional site into an adjacent octahedral site, the other contraction of four lattice atoms toward the guest atom. This localized pair potential approach was used successfully to identify the origin of pairs of emission bands in the $\mathrm{Zn} / \mathrm{Ar}, \mathrm{Zn} / \mathrm{Kr}$, and $\mathrm{Zn} / \mathrm{Xe}$ systems as being due to the existence of two energy-lowering vibronic modes in the excited ${ }^{1} \mathrm{~T}_{1 \mathrm{u}}$ state. The pair potential method is now applied to matrixisolated atomic cadmium where size effects, arising from this larger guest atom occupying the fixed site sizes in the solid rare gases, should be identifiable.

A summary of the luminescence recorded for the $\mathrm{Cd} / \mathrm{RG}$ solids is shown in Figure 1. Optical measurements were

\footnotetext{
† Part of the special issue "Marilyn Jacox Festschrift".

* To whom correspondence should be addressed.
}

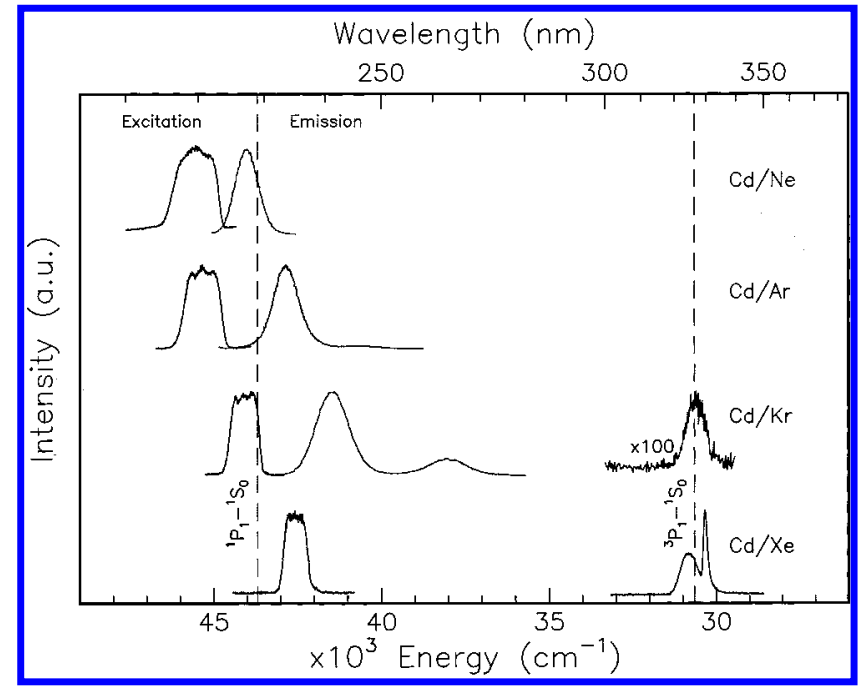

Figure 1. Excitation and emission profiles recorded at $4 \mathrm{~K}$ for annealed $\mathrm{Cd} / \mathrm{RG}$ samples. For comparison, the $5 \mathrm{~s}^{1} 5 \mathrm{p}^{1}{ }^{1} \mathrm{P}_{1} \leftrightarrow 5 \mathrm{~s}^{2}{ }^{1} \mathrm{~S}_{0}$ and $5 \mathrm{~s}^{1} 5 \mathrm{p}^{1}{ }^{3} \mathrm{P}_{1}$ $\leftrightarrow 5 \mathrm{~s}^{2}{ }^{1} \mathrm{~S}_{0}$ gas-phase transitions of atomic cadmium are included. All features have been normalized for clarity. An indication of the weakness of the $\mathrm{Cd} / \mathrm{Kr}$ triplet emission compared with the singlet emission band at $241.5 \mathrm{~nm}$ is given by the indicated gain.

conducted at the HIGITI experimental station in HASYLAB at DESY, Hamburg, utilizing synchrotron radiation. The experimental setup has been presented in detail before. ${ }^{4}$ Solid $\mathrm{Cd} / \mathrm{RG}$ samples were prepared by the cocondensation of cadmium metal vapor, produced by electron bombardment of $1 \mathrm{~mm}$ thick cadmium foil coiled in a molybdenum crucible in an Omicron EFM3 UHV evaporator, with the rare gases. As shown in Figure 
1, both $\mathrm{Cd} / \mathrm{Ne}$ and $\mathrm{Cd} / \mathrm{Ar}$ have one emission band assigned, from lifetime measurements, ${ }^{4}$ to the singlet $5 \mathrm{~s}^{1} 5 \mathrm{p}^{1}{ }^{1} \mathrm{P}_{1} \rightarrow 5 \mathrm{~s}^{2}{ }^{1} \mathrm{~S}_{0}$ transition. In $\mathrm{Cd} / \mathrm{Kr}$, as in the $\mathrm{Zn} / \mathrm{Ar}$ and $\mathrm{Zn} / \mathrm{Kr}$ systems, ${ }^{2}$ a pair of emission bands is observed, both of which are assigned to the singlet transition. Sample annealing ${ }^{4}$ showed that the pair of $\mathrm{Cd} / \mathrm{Kr}$ bands arise from a single thermally stable site. The absorption features of the $\mathrm{Cd} / \mathrm{Ar}, \mathrm{Cd} / \mathrm{Kr}$, and $\mathrm{Cd} / \mathrm{Xe}$ systems show a 3 -fold splitting pattern ${ }^{4}$ that is not evident in the $\mathrm{Cd} / \mathrm{Ne}$ absorption feature. ${ }^{4,6} \mathrm{Cd} / \mathrm{Xe}$ has two long-lived emission bands in the near-UV region that, based on their spectral locations, are assigned to $5 \mathrm{~s}^{1} 5 \mathrm{p}^{1}{ }^{3} \mathrm{P}_{\mathrm{J}} \rightarrow 5 \mathrm{~s}^{2}{ }^{1} \mathrm{~S}_{0}$ transitions. Because of their long decay times, only tentative $J$ value assignments have been made because of the lack of precise lifetimes ${ }^{4}$ when measurement attempts were made using high repetition synchrotron radiation for excitation.

The task of the present work is to simulate the $\mathrm{Cd} / \mathrm{RG}$ matrix emission using a localized pair potentials approach. Its objective is an examination of the approach, applied with success in the $\mathrm{Zn} / \mathrm{RG}$ matrix systems, to identify the effect of this larger guest in the well-defined site sizes of the solid rare gases. The paper is organized as follows. First, gas-phase type calculations are done for atomic $\mathrm{Cd}$ interacting with rare gas cluster systems. These calculations provide an insight into the interactions occurring in the solid state, which are then calculated.

\section{Method}

A localized approach is adopted to simulate the energies of the solid-state $\mathrm{Cd} / \mathrm{RG}$ systems involving pairwise-summing of the interactions between the guest $\mathrm{Cd}$ atom and a limited number of host atoms. The method employed is that developed by Beswick and co-workers ${ }^{7,8}$ in a simulation of the vibronic structure of the gas-phase triatomic $\mathrm{Hg}\left({ }^{3} \mathrm{P}_{1}\right) \cdot \mathrm{Ar}_{2}$ complex. Crepin and Tramer $^{3}$ made initial attempts at applying this method to the $\mathrm{Hg}\left({ }^{3} \mathrm{P}_{1}\right) / \mathrm{RG}$ matrix systems. More recently, calculations on the solid-state $\mathrm{Zn}\left({ }^{1} \mathrm{P}_{1}\right) / \mathrm{RG}$ systems were performed by McCaffrey and Kerins ${ }^{5,9}$ to explain the origin of the observed pairs of matrix emission bands.

The two key assumptions in the method are (1) that the energy of the multibody system, cluster, or solid state is calculated from the sum of metal atom-rare gas atom interactions and (2) that the interactions in the solid state are short range. In Table 1 the $\mathrm{Cd} \cdot \mathrm{RG}$ pair-potential parameters used for the $\mathrm{Cd} / \mathrm{RG}$ matrix simulations are presented. These parameters have been obtained from the work of Breckenridge and co-workers. ${ }^{10,11}$ Laserinduced fluorescence spectroscopy was used in the derivation of parameters needed for the bound ground $\mathrm{X}^{1} \Sigma_{0}$ and excited $\mathrm{C}^{1} \Pi_{1}$ and $\mathrm{D}^{1} \Sigma$ states of the $\mathrm{Cd} \cdot \mathrm{RG}$ diatomics. In Figure 2 , the $\mathrm{Cd} \cdot \mathrm{Kr}$ potential energy curves and their associated orbital interactions in the ground $\mathrm{X}^{1} \Sigma_{0}$ and excited $\mathrm{D}^{1} \Sigma$ and $\mathrm{C}^{1} \Pi_{1}$ states are depicted. Both the ground $\mathrm{X}^{1} \Sigma_{0}$ and excited $\mathrm{D}^{1} \Sigma$ state curves were originally represented by the Buckingham functions, ${ }^{12}$ of the form $A \mathrm{e}^{-b R}-C_{6} / R^{6}$, listed in Table 2. In the present work, the original $\mathrm{D}^{1} \Sigma$ curve is fit to a Morse function in order to remove the nonphysical behavior in the Buckingham potential energy function, evident in the right panel of Figure 3, below 3.3 $\AA$. The ground-state $\mathrm{RG} \cdot \mathrm{RG}$ parameters used were the values listed by Kaup and Breckenridge. ${ }^{13}$

\section{Calculations and Results}

Only an outline of the calculations will be given here because they have already been described elsewhere ${ }^{5}$ in detail. In the ground electronic state, the cluster potential $W_{X}(R)$ is given by
TABLE 1: Morse $D_{\mathrm{e}}\left[1-\mathrm{e}^{-\beta\left(R-R_{\mathrm{e}}\right)}\right]^{2}$ and Repulsive Exponential $\left(A \mathrm{e}^{-b R}\right)$ Function Parameters Used as Bound and Free State Pair Potentials, Respectively, for Atomic Rare Gas-Rare Gas and Cadmium-Rare Gas Atom Interactions $^{a}$

\begin{tabular}{lcllll}
\hline \multicolumn{1}{c}{ diatomic } & $D_{\mathrm{e}}\left(\mathrm{cm}^{-1}\right)$ & $R_{\mathrm{e}}(\AA)$ & $\beta\left(\AA^{-1}\right)$ & $A\left(\times 10^{7} \mathrm{~cm}^{-1}\right)$ & $b\left(\AA^{-1}\right)$ \\
\hline $\mathrm{Ne} \cdot \mathrm{Ne}\left(\mathrm{X}^{1} \sum\right)$ & 29.413 & 3.090 & 2.839 & & \\
$\mathrm{Ar} \cdot \mathrm{Ar}\left(\mathrm{X}^{1} \sum\right)$ & 99.2 & 3.761 & 1.685 & & \\
$\mathrm{Kr} \cdot \mathrm{Kr}\left(\mathrm{X}^{1} \sum\right)$ & 138.4 & 4.017 & 1.604 & & \\
$\mathrm{Xe} \cdot \mathrm{Xe}\left(\mathrm{X}^{1} \sum\right)$ & 196.24 & 4.3634 & 1.509 & & \\
$\mathrm{Cd} \cdot \mathrm{Ne}\left(\mathrm{X}^{1} \sum\right)$ & 39 & 4.26 & 1.0785 & & \\
$\mathrm{Cd} \cdot \mathrm{Ar}\left(\mathrm{X}^{1} \sum\right)$ & 106 & 4.31 & 1.212 & & \\
$\mathrm{Cd} \cdot \mathrm{Kr}\left(\mathrm{X}^{1} \sum\right)$ & 128 & 4.33 & 1.28 & & \\
$\mathrm{Cd} \cdot \mathrm{Xe}\left(\mathrm{X}^{1} \sum\right)$ & 187 & 4.55 & 0.9917 & & \\
$\mathrm{Cd} \cdot \mathrm{Ne}\left(\mathrm{C}^{1} \Pi\right)$ & 89 & 3.61 & 1.350 & & \\
$\mathrm{Cd} \cdot \mathrm{Ar}\left(\mathrm{C}^{1} \Pi\right)$ & 544 & 3.28 & 1.399 & & \\
$\mathrm{Cd} \cdot \mathrm{Kr}\left(\mathrm{C}^{1} \Pi\right)$ & 1036 & 3.17 & 1.5236 & & \\
$\mathrm{Cd} \cdot \mathrm{Xe}\left(\mathrm{C}^{1} \Pi\right)$ & 2485 & 3.26 & 1.6686 & & \\
$\mathrm{Cd} \cdot \mathrm{Ne}\left(\mathrm{D}^{1} \sum\right)$ & & & & $1.537791^{d}$ & $2.9408^{d}$ \\
$\mathrm{Cd} \cdot \mathrm{Ar}\left(\mathrm{D}^{1} \sum\right)$ & & & & $0.068136^{b}$ & $1.7775^{b}$ \\
$\mathrm{Cd} \cdot \mathrm{Kr}\left(\mathrm{D}^{1} \sum\right)$ & $79.51^{c}$ & $5.977 c$ & $0.715^{c}$ & & \\
$\mathrm{Cd} \cdot \mathrm{Xe}\left(\mathrm{D}^{1} \sum\right)$ & & & & $1.5856^{d}$ & $2.35627^{d}$
\end{tabular}

${ }^{a}$ The $\mathrm{Cd} \cdot \mathrm{RG}$ parameters were obtained from refs 10 and 11 and the $\mathrm{RG} \cdot \mathrm{RG}$ data from ref $12 .{ }^{b}$ Repulsive exponential function fitted to $A$ $\mathrm{e}^{-b R}-C_{6} / R^{6}$ potential energy curve. ${ }^{c}$ Morse function fitted to $A \mathrm{e}^{-b R}-$ $C_{6} / R^{6}$ potential energy curve. ${ }^{d}$ Estimated fits of plots in refs 10 and 11.

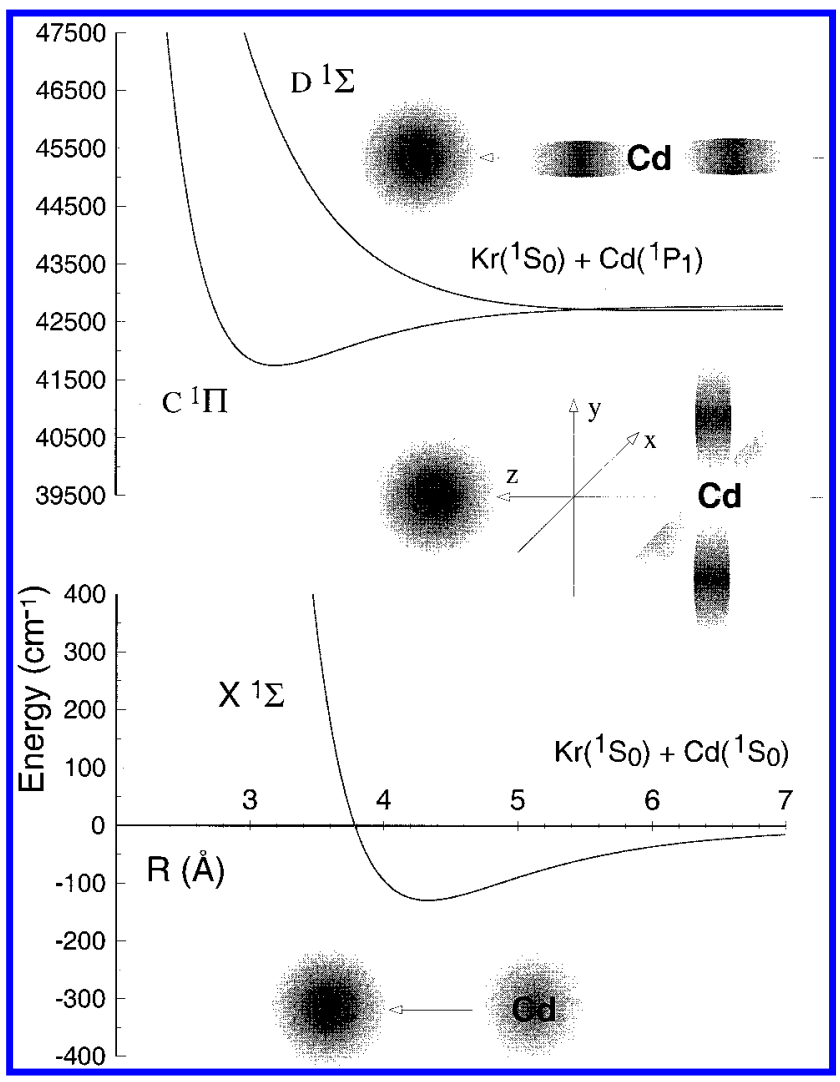

Figure 2. Potential energy curves of the diatomic van der Waals molecule $\mathrm{Cd} \cdot \mathrm{Kr}$ induced by the interaction of the $\mathrm{Cd}{ }^{1} \mathrm{~S}_{0}$ ground and ${ }^{1} \mathrm{P}_{1}$ excited state with the krypton ${ }^{1} \mathrm{~S}_{0}$ state.

where $k$ is the number and $R_{k}$ the length of the cadmium atomrare gas atom bonds in the cluster and $m$ represents the number of rare gas - rare gas interactions involved in the $\mathrm{Cd} \cdot \mathrm{RG}_{n}$ cluster. Since transition energies are being calculated in the spectral simulations, the $V_{\mathrm{RG}-\mathrm{RG}}$ term will only be stated explicitly in the expressions following when a change in the RG-RG bond length occurs. Formulas of the first excited electronic state $\mathrm{Cd}-$ $\left({ }^{1} \mathrm{P}_{1}\right) \cdot \mathrm{RG}_{n}$ are more difficult to obtain than that of the ground state because of the nonzero electronic angular momentum 
TABLE 2: Original Parameters for the $\mathbf{C d} \cdot \mathbf{K r} \mathbf{D}^{1} \Sigma$ Excited State from Ref $10^{a}$

\begin{tabular}{|c|c|c|c|c|}
\hline \multicolumn{5}{|c|}{$\mathrm{D}^{1} \sum$ State } \\
\hline & range $(\AA)$ & $A\left(\mathrm{~cm}^{-1}\right)$ & $b\left(\AA^{-1}\right)$ & $C_{6}\left(\mathrm{~cm}^{-1} \AA^{6}\right)$ \\
\hline $\mathrm{Cd} \cdot \mathrm{Ar}$ & $3.7-5.0$ & -4.5979 & -0.6758 & $-2.5767 \times 10^{6}$ \\
\hline $\mathrm{Cd} \cdot \mathrm{Kr}$ & $3.8-5.0$ & $1.4731 \times 10^{6}$ & 1.5399 & $1.0396 \times 10^{7}$ \\
\hline \multicolumn{5}{|c|}{$\mathrm{X}^{1} \sum$ State } \\
\hline \multicolumn{3}{|c|}{$A\left(\mathrm{~cm}^{-1}\right)$} & $b\left(\AA^{-1}\right)$ & $C_{6}\left(\mathrm{~cm}^{-1} \AA^{6}\right)$ \\
\hline $\mathrm{Cd} \cdot \mathrm{A}$ & \multirow{2}{*}{\multicolumn{2}{|c|}{$\begin{array}{l}1.116 \times 10^{7} \\
1.7026 \times 10^{7}\end{array}$}} & 2.6618 & $1.4244 \times 10^{6}$ \\
\hline $\mathrm{Cd} \cdot \mathrm{K}$ & & & $1.7026 \times 10^{\prime}$ & $1.7433 \times 10^{6}$ \\
\hline
\end{tabular}

${ }^{a}$ The ranges given for the $\mathrm{D}^{1} \sum$ state are used to fit the model potential to the experimental data.

$$
W_{X}(R)=\sum_{k=1}^{n} V_{\mathrm{Cd} \cdot \mathrm{RG}}\left(R_{k}\right)+\sum_{j=1}^{m} V_{\mathrm{RG} \cdot \mathrm{RG}}\left(r_{j}\right)
$$

(EAM) of the ${ }^{1} \mathrm{P}_{1}$ level. The formulas are obtained by projecting the EAM of the diatomic $\mathrm{Cd}-\mathrm{RG}$ axis onto the cluster axis using Wigner rotation matrices. ${ }^{14}$ Because of the axial symmetry of the $\mathrm{Cd}\left({ }^{1} \mathrm{P}_{1}\right)$ state, the following three cluster potentials, $W_{n^{-}}$ $(R)$,

$$
\mathrm{p}_{z}: \quad W_{1}(R)=\sum_{k=1}^{n} \cos ^{2} \theta_{k} V_{\Sigma}\left(R_{k}\right)+\sin ^{2} \theta_{\mathrm{k}} V_{\Pi}\left(R_{k}\right)
$$

$\mathrm{p}_{x}:$

$$
\begin{array}{r}
W_{2}(R)=\sum_{k=1}^{n} \sin ^{2} \theta_{\mathrm{k}} \cos ^{2} \phi_{k} V_{\Sigma}\left(R_{k}\right)+ \\
{\left[\cos ^{2} \theta_{k} \cos ^{2} \phi_{k}+\right.} \\
\left.\sin ^{2} \phi_{k}\right] V_{\Pi}\left(R_{k}\right)
\end{array}
$$

$\mathrm{p}_{y}:$

$$
\begin{array}{r}
W_{3}(R)=\sum_{k=1}^{n} \sin ^{2} \theta_{k} \sin ^{2} \phi_{k} V_{\Sigma}\left(R_{k}\right)+ \\
{\left[\cos ^{2} \theta_{k} \sin ^{2} \phi_{k}+\right.} \\
\left.\cos ^{2} \phi_{k}\right] V_{\Pi}\left(R_{k}\right)
\end{array}
$$

arise for the three atomic p orbitals. In eqs $2-4$, the $C^{1} \Pi_{1}$ and $\mathrm{D}^{1} \Sigma$ state potentials of the $\mathrm{Cd} \cdot \mathrm{RG}$ diatomics are represented as $V_{\Pi}$ and $V_{\Sigma}$, respectively. The meanings of the variables $\theta$ and $\phi$ are illustrated in Figure 4, which shows a $\mathrm{Cd} \mathrm{p}_{z}$ orbital approaching perpendicular to a plane containing four rare gas atoms arranged in a square. $\theta_{k}$ are the angles between the approach axis of the $\mathrm{Cd} \mathrm{p}_{z}$ orbital and the rare gas atoms in the cluster species, $\phi_{k}$ are the angles between the rare gas atoms in the square plane. $R_{\mathrm{CM}}$ is the distance of the $\mathrm{Cd}$ atom to the center-of-mass of the rare gas cluster. Thus, in the treatment used, direct pairwise addition of the potentials is only done for the ground state with eq 1 . In the excited state, the angular dependence is accounted for in eqs $2-4$ prior to addition of the potentials.

Clusters. Calculations were performed on the $\mathrm{Cd} \cdot \mathrm{RG}_{n}$ clusters, with $n=3,4,5$, or 6 . The Cd atom is permitted to approach perpendicular to the planar arrangement of rare gas atoms as shown in Figure 4. The cluster potential energies for the $C_{4 v}, n=4$ case were obtained by substituting the values $\pi / 2, \pi, 3 \pi / 2$, and $2 \pi$ for $\phi_{k}$ into eqs $2-4$. The following expressions were derived upon evaluation of the sums

$$
\begin{gathered}
W_{\mathrm{A} 1}(R)=4\left[\cos ^{2} \theta V_{\Sigma}(R)+\sin ^{2} \theta V_{\Pi}(R)\right] \\
W_{\mathrm{E}}(R)=2\left[\sin ^{2} \theta V_{\Sigma}(R)+\left(\cos ^{2} \theta+1\right) V_{\Pi}(R)\right]
\end{gathered}
$$

where $\mathrm{Cd}\left(\mathrm{p}_{z}\right) \cdot \mathrm{RG}_{n}$ and $\mathrm{Cd}\left(\mathrm{p}_{x}, \mathrm{p}_{y}\right) \cdot \mathrm{RG}_{n}$ interactions are now represented by the ${ }^{1} \mathrm{~A}_{1}$ and doubly degenerate ${ }^{1} \mathrm{E}$ electronic states, respectively. In the high-symmetry $C_{4 v}$ cluster, a single $R$ replaces $R_{k}, R$ being defined as

$$
\sqrt{R_{\mathrm{CM}}^{2}+\left(r_{\mathrm{e}} / \sqrt{2}\right)^{2}}
$$

where $r_{\mathrm{e}}$ is the rare gas dimer bond length in the cluster.

In Figure 5, the ${ }^{1} \mathrm{~A}_{1}$ state potential curves are shown for the approach of the $\mathrm{p}_{z}$ orbital to the planar $\mathrm{Kr}_{n}$ clusters, $n=3,4$, 5 , or 6 . For $n=3$ no stability was obtained, but for the other clusters maximum stabilization is attained at $R_{\mathrm{CM}}=0$, where the $\mathrm{Cd} \mathrm{p}_{z}$ orbital is located at the center of the planar rare gas arrangements. It is evident in Figure 5 that the $\mathrm{Cd}\left({ }^{1} \mathrm{P}_{1}\right) \cdot \mathrm{RG}_{5}$ cluster is the most stable system, as demonstrated by its large binding energy of $4670.3 \mathrm{~cm}^{-1}$. These results were also obtained for the other rare gas systems analyzed, with the exception of neon where the $\mathrm{Cd}\left({ }^{1} \mathrm{P}_{1}\right) \cdot \mathrm{Ne}_{6}$ cluster was the only one showing stabilization. Calculations of the ${ }^{1} \mathrm{E}$ states, although not shown, indicated energy increases; i.e., the interactions become repulsive as the $\mathrm{Cd}\left(\mathrm{p}_{x}, \mathrm{p}_{y}\right)$ orbitals approach the centers of the rare gas clusters. Thus, in the analysis of the luminescence in these cluster species, only the ${ }^{1} \mathrm{~A}_{1}$ state will be considered ${ }^{15}$ because of it being the only one to bring about a lowering of the excitedstate energy.

Calculations were also done to obtain the potential energy of an excited ${ }^{1} \mathrm{P}_{1}$ state $\mathrm{Cd}$ atom advancing in a $C_{4 v}$ approach toward the base of a square pyramidal $\mathrm{RG}_{5}$ cluster. The result of this cluster calculation is of importance to the solid state because it corresponds to the motion of a guest atom into an octahedral interstitial site of the lattice. In this $C_{4 v}$ calculation, the four rare gas atoms making up the base of the square pyramid are arranged perpendicular to the $\mathrm{Cd}$ atom, and the fifth apex atom is positioned on the approach axis. As the $\mathrm{Cd}$ $\mathrm{p}_{z}$ orbital moves toward the center of this base, it will experience repulsion from the apical rare gas atom. Thus, when the energy of the ${ }^{1} \mathrm{~A}_{1}$ state is evaluated, the repulsive term $V_{\Sigma}(R+r)$ must be added to eq 5, where $r$ is the distance from the center of the base of the square pyramid to the apex. Equation 6, allowing calculation of the ${ }^{1} \mathrm{E}$ state, will have an attractive $V_{\Pi}(R+r)$ term included for the $\mathrm{p}_{x}, \mathrm{p}_{y}$ approach. In Figure 6, the energy calculations of the ${ }^{1} \mathrm{~A}_{1}$ and ${ }^{1} \mathrm{E}$ states are shown for the $\mathrm{Cd} \cdot \mathrm{Kr}_{5}$ system in a $C_{4 v}$ approach. It is readily seen that the energy minimum is not at $R=0$, observed for the planar $\mathrm{Cd} \cdot \mathrm{Kr}_{n}$ cluster calculations but is at a distance $1.04 \AA$ from the base of the $\mathrm{Kr}$ square pyramid. The reason for the difference originates from the apical $\mathrm{Kr}$ atom in the $\mathrm{Kr}_{5}$ structure, which does not allow the $\mathrm{Cd} \mathrm{p}_{z}$ orbital to reach the base of the pyramid, as repulsive forces are induced between the two atoms along this axis.

The $\mathrm{Cd}\left({ }^{1} \mathrm{P}_{1}\right) \cdot \mathrm{RG}_{n}$ cluster results can now be extended into the solid-state calculations because they give us an idea of the excited-state stabilization arising from motion of the atomic guest in the solid rare gas lattices.

Matrix. The solid rare gases have a face-centered cubic (fcc) packing structure. From a comparison of the $\mathrm{Cd} \cdot \mathrm{RG} \mathrm{X}^{1} \Sigma_{0}$ ground-state bond lengths with the site sizes listed in Table 3 for the solid rare gases, it is evident that the substitutional site provides the best match for most of the rare gases. Thus, the initial calculations were done by allowing the $\mathrm{Cd}$ atom to replace a single rare gas atom in the rare gas lattice. This substitutional site has cubooctahedral symmetry. Therefore, (1) equivalent interactions exist for $\mathrm{p}_{x}, \mathrm{p}_{y}$, and $\mathrm{p}_{z}$ orbital occupancy and (2) ${ }^{1} \mathrm{~A}_{1 \mathrm{~g}}$ and ${ }^{1} \mathrm{~T}_{1 \mathrm{u}}$ state labels replace the ${ }^{1} \mathrm{~S}_{0}$ and ${ }^{1} \mathrm{P}_{1}$ designations, respectively. 


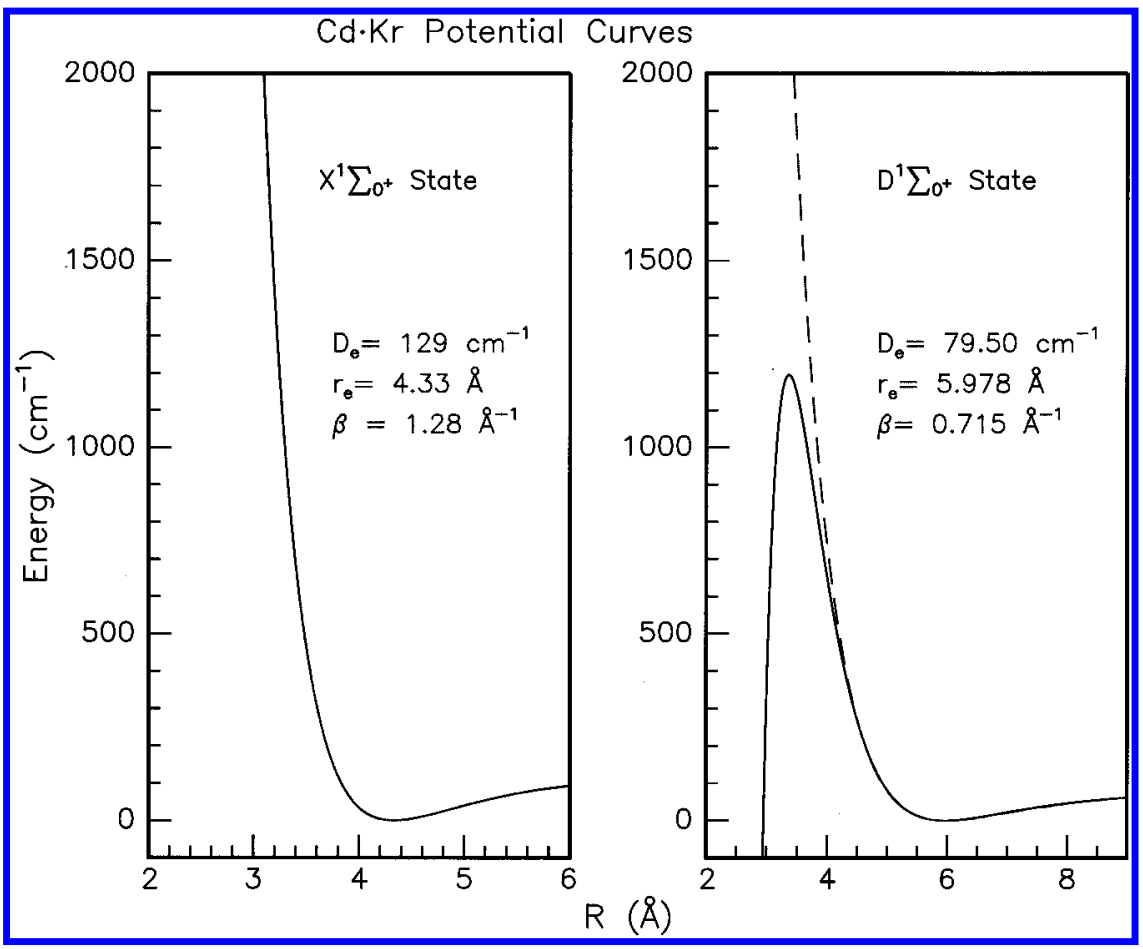

Figure 3. Fit of a Morse function $D_{\mathrm{e}}\left[1-\mathrm{e}^{-\beta\left(R-R_{\mathrm{e}}\right)}\right]^{2}$ to the $\mathrm{Cd} \cdot \mathrm{Kr} \mathrm{X}^{1} \Sigma_{0}$ and $\mathrm{D}^{1} \Sigma$ potential energy curves represented by the function $A \mathrm{e}^{-b R}-C_{6} / R^{6}$ of ref 10 . As can be seen in the right panel, the original $\mathrm{D}^{1} \Sigma$ potential energy curve, indicated by the solid line, exhibits nonphysical behavior below $3.3 \AA$. The fit, shown by the broken line, was applied to the range 4.9-9.0 $\AA$. For the ground state, a Morse fit to the Buckingham function is identical to the original.

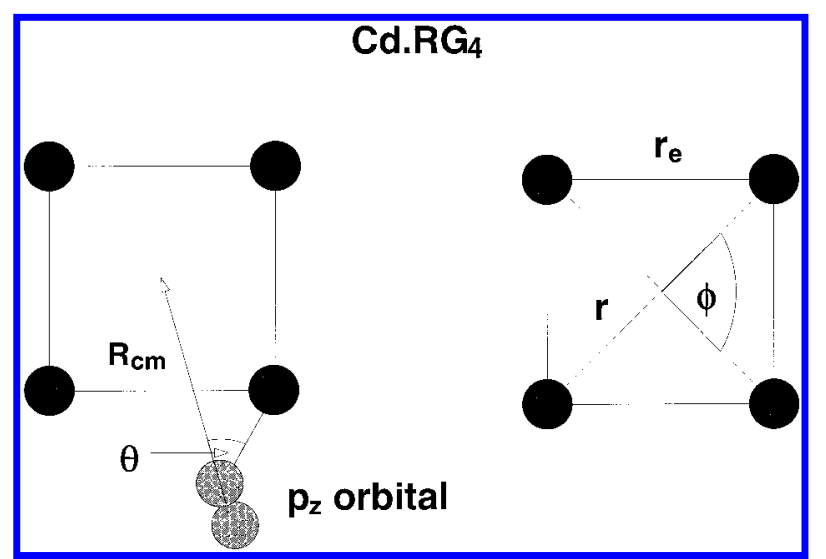

Figure 4. Diagram of the cadmium $\mathrm{p}_{z}$ orbital approaching a cluster of four rare gas atoms, i.e., $\mathrm{Cd}\left({ }^{1} \mathrm{P}_{1}\right) \cdot \mathrm{RG}_{4}$. The angles $\theta$ and $\phi$, which are specified in eqs $2-4$, are shown along with the distance variables $r$ and $r_{\mathrm{e}}$, which are defined as the distance of each rare gas atom to the cluster center-of-mass and the rare gas-rare gas bond length, respectively.

Besides the dominant interaction of the $\mathrm{Cd}$ atom with the 12 nearest rare gas neighbors, the interaction of the $\mathrm{Cd}$ atom with the six next-nearest neighbors is needed in order to provide the required $\mathrm{p}$ orbital equivalency. Thus, the $18 \mathrm{Cd}-\mathrm{RG}$ interactions depicted in Figure 7 are considered. The labels $\mathrm{I}_{\mathrm{oh}} 1$ and $\mathrm{I}_{\mathrm{oh}} 2$ in Figure 7 denote the octahedral interstitial sites and will be important when looking at the atomic motion in the excited state.

According to the $\mathrm{Cd} \cdot \mathrm{Kr}_{n}$ cluster calculations shown in Figure 5 , the interaction one should look for in the solid state to attain the greatest excited-state stabilization is the $\mathrm{Cd}\left(\mathrm{p}_{z}\right)$ atom located at the center of a planar arrangement of five nearest-neighbor krypton atoms. However, in view of the 4-fold symmetry in the fcc lattice, this is not possible because planar arrangements of only four and six $\mathrm{Kr}$ atoms are possible for the 12 nearestneighbor atoms surrounding the $\mathrm{Cd}$ guest in a substitutional site. Instead, we look at the dominant interaction between the $\mathrm{Cd}$

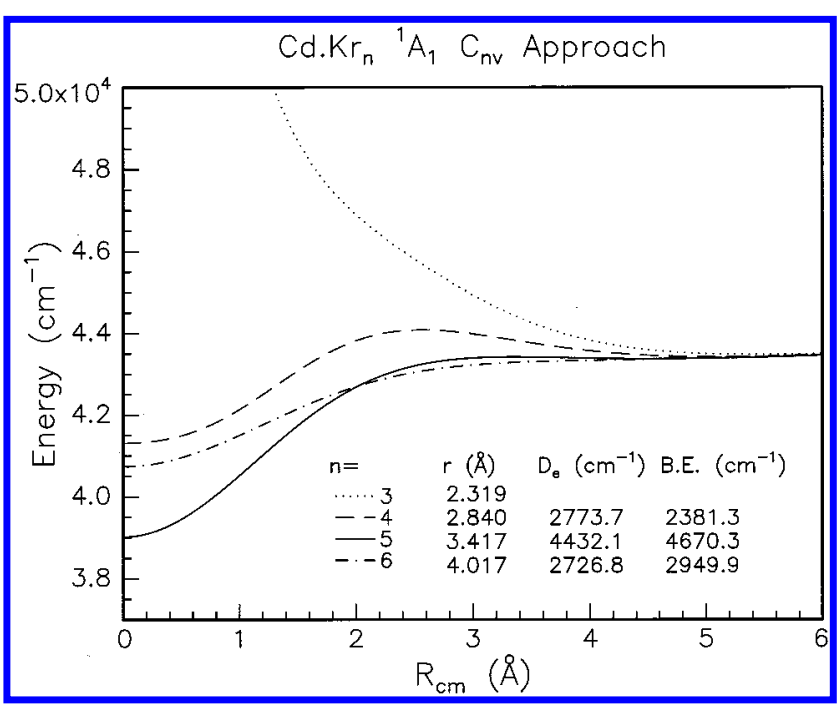

Figure 5. Potential energy plotted against the distance associated with the perpendicular approach of the cadmium $\mathrm{p}_{z}$ orbital toward the centerof-mass of the planar rare gas clusters $\mathrm{Cd} \cdot \mathrm{Kr}_{n}, n=3,4,5$, or 6 . The greatest stability is attained for $n=5$, but the $n=4$ system is of more significance to the matrix system because of the 4-fold symmetry of the solid rare gases. Also the $\mathrm{C}^{1} \Pi_{1}$ bond length is $3.17 \AA$, but the $\mathrm{Kr}_{4}$ square-planar cluster has an $r$ value (see Figure 4) of $2.84 \AA$, which shows there is only a slight degree of "crampness" in the $\mathrm{Cd} \cdot \mathrm{Kr}_{4}$ system.

atom and four of its nearest neighbors as was done for the $\mathrm{Zn} /$ RG calculations. ${ }^{5}$ Figure 8 allows a visual representation of two possible motions involving a dominant interaction of the $\mathrm{Cd}$ atom with four $\mathrm{Kr}$ atoms. It will be shown later that both of these motions lower the energy in the degenerate ${ }^{1} \mathrm{~T}_{1 \mathrm{u}}$ excited state. The first motion considered is the movement of the $\mathrm{Cd}$ atom along the $Z$ axis of Figure 8 toward an octahedral interstitial site. This is called the "body" mode and is denoted by $\mathrm{Q}_{2}$. The other mode, labeled the "waist" mode $\left(\mathrm{Q}_{3}\right)$, involves 


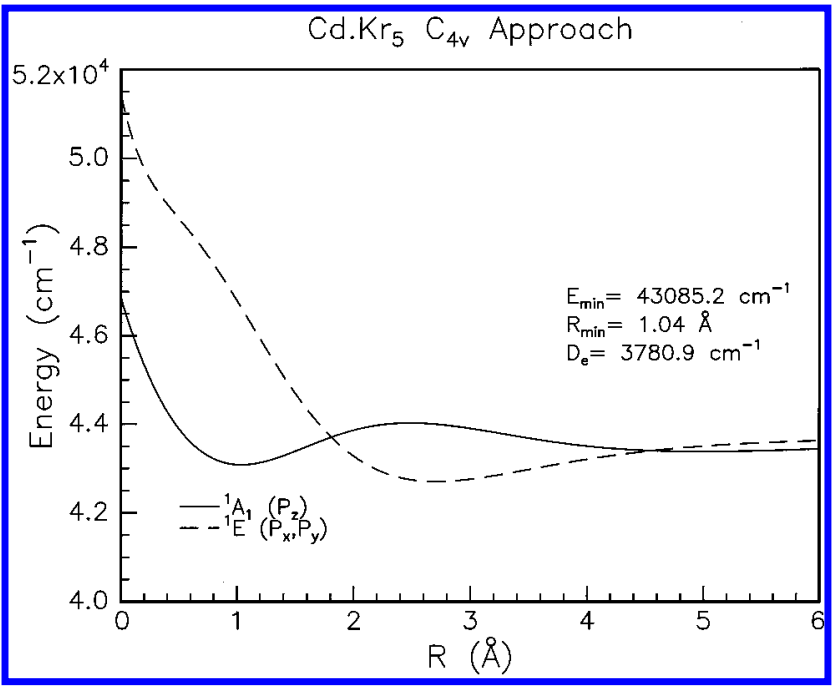

Figure 6. ${ }^{1} \mathrm{~A}_{1}$ and doubly degenerate ${ }^{1} \mathrm{E}$ potential energy curves calculated for the $C_{4 v} \mathrm{Cd} \cdot \mathrm{Kr}_{5}$ cluster utilizing expanded versions of eqs 5 and 6 . To extend eq 5 , a $V_{\Sigma}(R+r)$ is included because the $\mathrm{Cd} \mathrm{p}_{z}$ orbital experiences repulsion from the apical $\mathrm{Kr}$ atom. For eq 6 a $V_{\Pi^{-}}$ $(R+r)$ term is required to form the correct expression for the $\mathrm{Cd} \mathrm{p}_{x}, \mathrm{p}_{y}$ interaction.

TABLE 3: Comparison of the Cd・RG Internuclear Distances, $r_{\mathrm{e}}$, in Both the Ground $\left(\mathrm{X}^{1} \Sigma_{0}\right)$ and Excited $\left(\mathrm{C}^{1} \Pi_{1}\right)$ States with the Site Diameters of the Solid Rare Gases ${ }^{a}$

\begin{tabular}{cccccc}
\hline $\mathrm{RG}$ & $a$ & $\mathrm{I}_{\mathrm{oh}}$ site & Sub. site & $r_{\mathrm{e}}, \mathrm{X}^{1} \Sigma_{0}$ & $r_{\mathrm{e}}, \mathrm{C}^{1} \Pi_{1}$ \\
\hline $\mathrm{Ne}$ & 4.46 & 1.306 & 3.154 & 4.26 & 3.61 \\
$\mathrm{Ar}$ & 5.31 & 1.556 & 3.756 & 4.31 & 3.28 \\
$\mathrm{Kr}$ & 5.64 & 1.653 & 3.991 & 4.33 & 3.17 \\
$\mathrm{Xe}$ & 6.13 & 1.796 & 4.335 & 4.55 & 3.36
\end{tabular}

${ }^{a}$ All distances are in angstrom units, and the solid-state lattice parameters pertain to the values at $4 \mathrm{~K}$.

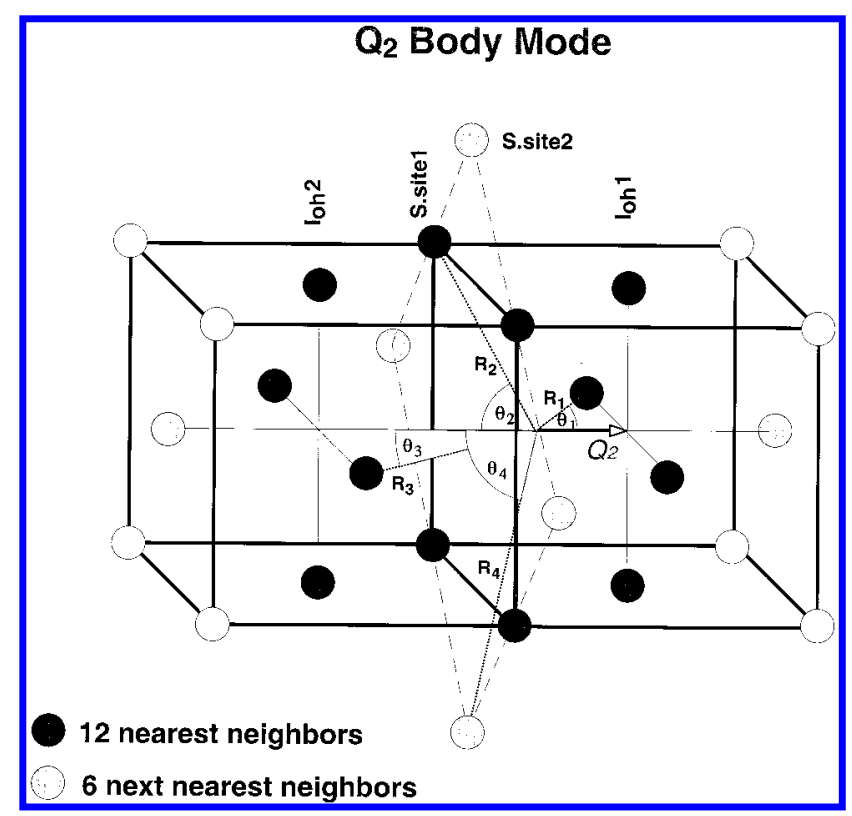

Figure 7. Diagram of a pair of adjacent fcc unit cells depicting the parameters associated with the "body mode" calculation for $\mathrm{Cd} / \mathrm{Kr}$. The $\mathrm{Cd}$ atom moves from S.site 1 along the $Z$ axis toward $\mathrm{I}_{\mathrm{oh}} 1$ denoted by $\mathrm{Q}_{2}$. The 12 nearest neighbors and 6 next-nearest neighbors have been shown because these atoms create the $\mathrm{p}_{x}, \mathrm{p}_{y}$, and $\mathrm{p}_{z}$ equivalency in interaction terms as the $\mathrm{Cd}$ atom resides in a substitutional site.

four $\mathrm{Kr}$ atoms in the lattice $X Y$ plane contracting in-phase toward the $\mathrm{Cd}$ atom.

(i) Body Mode. As the Cd atom moves from the substitutional site toward an adjacent octahedral interstitial site $\mathrm{I}_{\mathrm{oh}} 1$ (see Figure

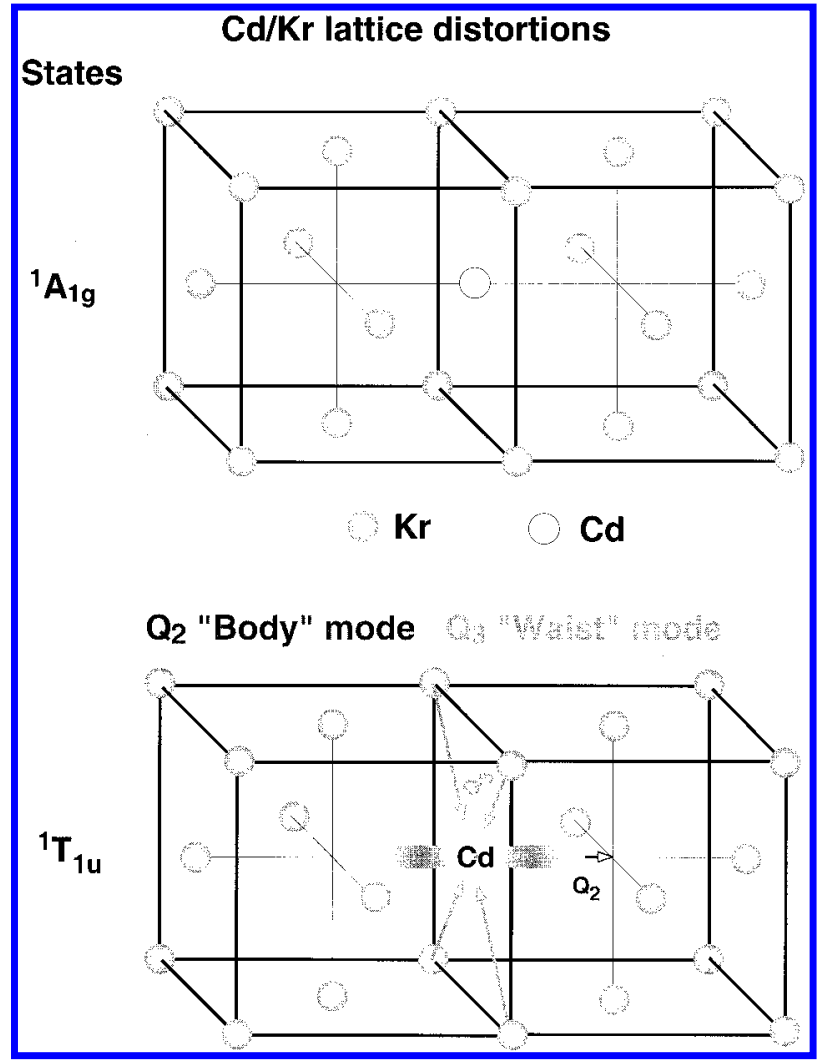

Figure 8. "Body $\left(\mathrm{Q}_{2}\right)$ " and "waist $\left(\mathrm{Q}_{3}\right)$ " mode motions within the pair of unit cells. The body mode involves the $\mathrm{Cd}\left(\mathrm{p}_{z}\right)$ atom moving along the $Z$ axis from the substitutional site it originally occupies in the ground state to an adjacent octahedral interstitial site. The waist mode consists of four rare gas atoms contracting in-phase toward the $\mathrm{Cd}$ atom.

7), four interactions must be taken into account in order to calculate the energy change arising from this motion. The four interactions all have 4-fold symmetry and are made up of the $C_{4 v} \mathrm{Cd}\left({ }^{1} \mathrm{P}_{1}\right) \cdot \mathrm{RG}_{4}$ and $\mathrm{Cd}\left({ }^{1} \mathrm{P}_{1}\right) \cdot \mathrm{RG}_{5}$ cluster calculations presented earlier. The $\mathrm{Cd}$ atom moves away from $\mathrm{I}_{\mathrm{oh}} 2$ but gets closer to $\mathrm{I}_{\mathrm{oh}} 1$ and also moves away from S.site 1 and S.site2 (movement toward either $\mathrm{I}_{\mathrm{oh}} 1$ or $\mathrm{I}_{\mathrm{oh}} 2$ will yield the same potential energy).

The general ${ }^{1} \mathrm{~A}_{1}$ state energy expression, $W\left(R_{n}, \theta_{n}\right)$, can be derived from eq 5 for this vibronic mode and will now depend on the variables $R_{n}$ and $\theta_{n}$,

$$
W\left(R_{n}, \theta_{n}\right)=4\left[\cos ^{2} \theta_{n} V_{\Sigma}\left(R_{n}\right)+\sin ^{2} \theta_{n} V_{\Pi}\left(R_{n}\right)\right]
$$

From here we can obtain the expressions for the four interactions:

$$
\begin{gathered}
W\left(R_{1}, \theta_{1}\right)+V_{\Sigma}(a-q): \quad \mathrm{I}_{\mathrm{oh}} 1 \\
W\left(R_{2}, \theta_{2}\right): \quad \text { S.site } 1 \\
W\left(R_{3}, \theta_{3}\right)+V_{\Sigma}(a+q): \quad \mathrm{I}_{\mathrm{oh}} 2 \\
W\left(R_{4}, \theta_{4}\right): \quad \text { S.site } 2
\end{gathered}
$$

The variable $q$ is the linear displacement of the $\mathrm{Cd} \mathrm{p}_{z}$ orbital away from S.site1, and $a$ is the lattice parameter of the solid rare gas unit cell. The energies of these four interactions and their sum in a "fixed" or rigid lattice is shown for the $\mathrm{CdKr}_{18}$ system in Figure 9. The $\mathrm{Cd}\left(\mathrm{p}_{z}\right)$ energy is calculated as the atom is displaced from the center of the substitutional site $(R=0)$ where it resided in the ground state. Maximum stabilization is achieved when the $\mathrm{Cd}$ atom has moved $1.49 \AA$ out of the substitutional site along the lattice $Z$ axis. The stabilization 


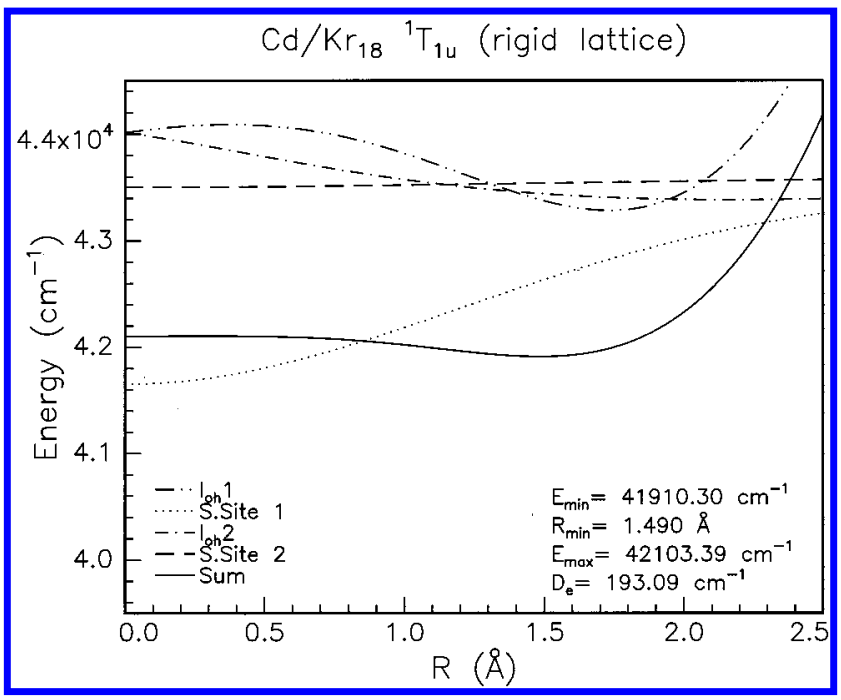

Figure 9. ${ }^{1} \mathrm{~T}_{1 \mathrm{u}}$ excited-state energy calculation of the $\mathrm{Cd} / \mathrm{Kr}$ body mode interaction. The energy is monitored as the $\mathrm{Cd}$ atom moves away from the substitutional site it occupies in the ground state. The four individual interactions are shown, and their sum is evaluated, which is the interaction of $\mathrm{Cd}$ with the 18 nearest neighbors.

energy at this displacement of $1.49 \AA$ is $193.09 \mathrm{~cm}^{-1}$ as shown in Figure 9. In the $\mathrm{Kr}$ lattice, the distance from the center of a substitutional site to an adjacent octahedral interstitial site is $2.82 \AA$, so at this energy minimum the $\mathrm{Cd}\left(\mathrm{p}_{z}\right)$ atom is positioned at a distance $1.33 \AA$ away from the center of the nearest octahedral interstitial site.

It should be possible for the ${ }^{1} \mathrm{~T}_{1 \mathrm{u}}$ electronic state to achieve a further lowering of its energy if the $\mathrm{Cd}$ atom is able to get closer to the center of the octahedral interstitial site, since there it will get nearer to achieving a complexation number of 4 . However, as the $\mathrm{Cd}$ atom approaches along the $Z$ axis to the center of these four $\mathrm{Kr}$ atoms, it will experience repulsion from the $\mathrm{Kr}$ atom lying on the end face, as shown in Figure 7. This $\mathrm{Kr}$ atom belongs to the previously described set of six nextnearest neighbor atoms. The energy of the excited state can be lowered if this end $\mathrm{Kr}$ atom moves into its adjacent $\mathrm{Kr}$ cell. This induces a destabilization within the $\mathrm{Kr}$ cell, but the $\mathrm{Cd}\left(\mathrm{p}_{z}\right)$ atom will be stabilized because it can now get closer to the octahedral interstitial site. When both the stabilization and destabilization forces are equal, the excited-state minimum energy is achieved. Calculations of the $\mathrm{Kr}$ movement are done by looking at a $\mathrm{Kr} \cdot \mathrm{Kr}_{17}$ system and substituting the appropriate $\mathrm{Kr}-\mathrm{Kr}$ ground-state diatomic rare gas parameters from Table 1 into eq 1 . The $\mathrm{Kr}$ atom moves $1.06 \AA$ into the next cell, inducing a destabilization energy of $882.7 \mathrm{~cm}^{-1}$ in the $\mathrm{Kr}$ lattice. The energy calculation of the $\mathrm{Cd}\left(\mathrm{p}_{z}\right)$ atom displacement is shown in Figure 10 and is called a relaxed lattice calculation. At the energy minimum the $\mathrm{Cd}\left(\mathrm{p}_{z}\right)$ atom has now moved $2.09 \AA$ away from the substitutional site originally occupied, producing a stabilization energy of $1098.6 \mathrm{~cm}^{-1}$. This is over 5 times bigger than the stabilization energy for the rigid lattice calculation. At the energy minimum, the $\mathrm{Cd}\left(\mathrm{p}_{z}\right)$ atom is situated $0.73 \AA$ away from the octahedral interstitial site. Thus, on only moving 0.6 $\AA$ further on, going from the rigid lattice calculation to its relaxed counterpart, a 5-fold increase in the stabilization energy is achieved.

These calculations were extended to the $\mathrm{Ne}, \mathrm{Ar}$, and $\mathrm{Xe}$ systems using the $\mathrm{Cd} \cdot \mathrm{RG}$ potentials listed in Table 1 . Figure 11 shows a summary of their relaxed lattice calculations as well as including the $\mathrm{Cd} / \mathrm{Kr}$ case previously shown in Figure 10 . Ground-state energies, denoted by the $E^{\prime \prime}$ values, are also shown

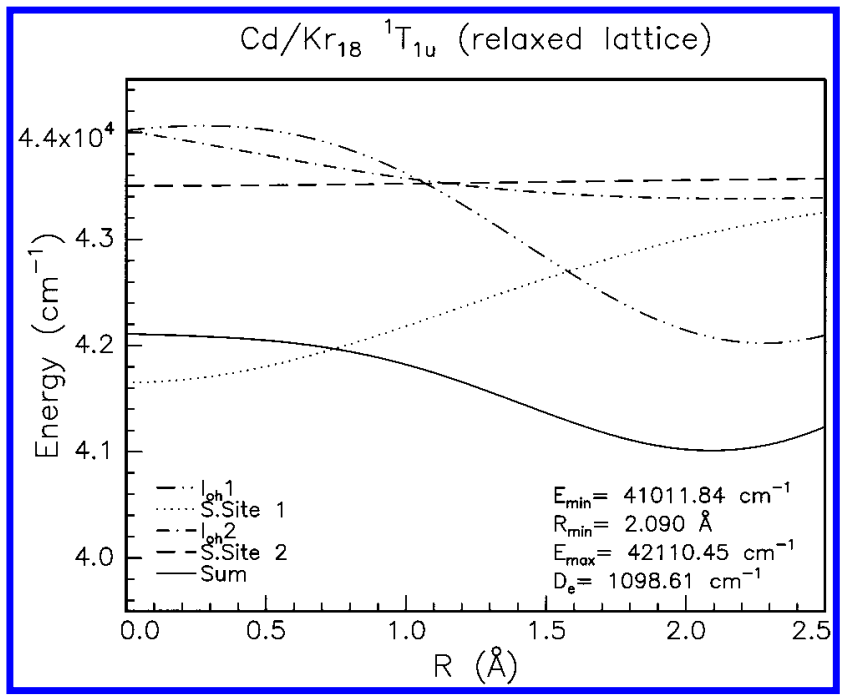

Figure 10. As in Figure 9 but for the movement of the "end" $\mathrm{Kr}$ atom into the next unit cell as the $\mathrm{Cd}\left(\mathrm{p}_{z}\right)$ atom gets closer to the octahedral interstitial site. This alleviates the stress within the $\mathrm{Cd} / \mathrm{Kr}$ system as the $\mathrm{Cd}\left(\mathrm{p}_{z}\right)$ "end" $\mathrm{Kr}$ atom repulsive interaction is lessened. The destabilization caused by the $\mathrm{Kr}$ atom entering the next unit cell is counteracted by the stabilization of the $\mathrm{Cd}$ atom getting closer to the octahedral interstitial site. When these forces are equal, the "body mode" energy minimum is achieved.

in this figure. It is evident from the calculations that as the $\mathrm{Cd}$ atom moves from the substitutional site it occupies in the ${ }^{1} \mathrm{~A}_{1 \mathrm{~g}}$ ground electronic state toward the octahedral interstitial site, no stabilization arises in the $\mathrm{Cd} / \mathrm{Ne}$ and $\mathrm{Cd} / \mathrm{Ar}$ systems. In contrast, the $\mathrm{Cd} / \mathrm{Kr}$ system, described in detail earlier, and the $\mathrm{Cd} / \mathrm{Xe}$ system show excited-state stabilization in the body mode motion.

Absorption and emission energies can now be calculated assuming that vertical Franck-Condon transitions take place between the ground and excited electronic states. The formulas for calculating both of these energies are the following:

$$
\begin{gathered}
E_{\mathrm{em}}\left(\mathrm{cm}^{-1}\right)=E^{\prime}\left(R_{\mathrm{min}}^{\prime}\right)-E^{\prime \prime}\left(R_{\min }^{\prime}\right)-E_{\mathrm{Rg} \cdot \mathrm{Rg}} \\
E_{\mathrm{abs}}\left(\mathrm{cm}^{-1}\right)=E^{\prime}(R=0)-E^{\prime \prime}(\mathrm{R}=0)
\end{gathered}
$$

where $E_{\mathrm{Rg} \cdot \mathrm{Rg}}$ is the distortion energy in the rare gas lattice as the end rare gas atom is moved into its adjacent cell.

The predicted and recorded absorption energies are listed in Table 4 . For the body mode of the $\mathrm{Cd} / \mathrm{Kr}$ and $\mathrm{Cd} / \mathrm{Xe}$ systems, there is relatively good agreement between the predicted and experimental results, but for $\mathrm{Cd} / \mathrm{Ar}$ and especially $\mathrm{Cd} / \mathrm{Ne}$ the agreement is poor. The calculated emission energies do not compare favorably with the recorded values, as seen in Table 5. The reason for the large discrepancy in the $\mathrm{Cd} / \mathrm{Kr}$ system is thought to be due to the $\mathrm{Cd} \cdot \mathrm{Kr}$ ground-state potential curve being too repulsive. This problem arises because of the large extrapolation of the $\mathrm{Cd} \cdot \mathrm{RG}$ ground-state potential required to obtain energies at the short $\mathrm{Cd} \cdot \mathrm{Kr}$ bond length $(\sim 2.8 \AA)$ existing at the stabilization displacement values $\left(R_{\min }^{\prime}\right)$ in the excited state.

(ii) Waist Mode. The waist mode calculation is more straightforward than the body mode because it only involves a single variable, the in-phase contraction of four rare gas atoms (S.site1) toward the $\mathrm{Cd}$ atom. An overview of the interactions involved is shown in Figure 12. The contraction of the four rare gas atoms involves a single variable $R_{2}$. There is also a fixed contribution from the two square-pyramid interactions belonging to $\mathrm{I}_{\mathrm{oh}} 1$ and $\mathrm{I}_{\mathrm{oh}} 2$ situated at fixed distances $R_{1}$ and $R_{3}$ 


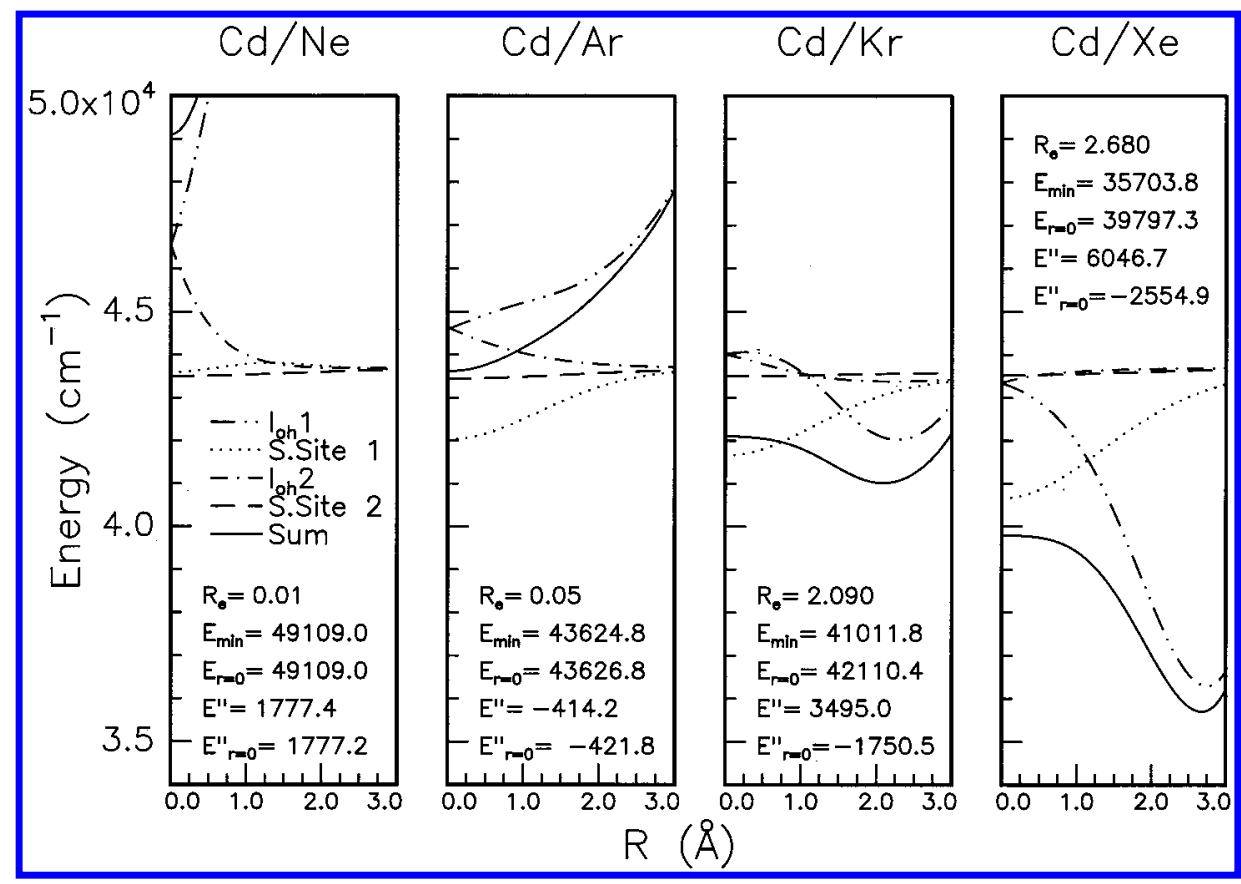

Figure 11. Body mode potential energy calculations for all the analyzed $\mathrm{Cd} / \mathrm{RG}$ systems. Stabilization occurs for only $\mathrm{Cd} / \mathrm{Kr}$ and $\mathrm{Cd} / \mathrm{Xe} \mathrm{during}$ this vibronic motion. Ground-state parameters are denoted by the "double prime" feature, although the potential energy curves from which they are calculated are not shown here. $E_{\min }$ denotes the energy value at which the stabilization and destabilization forces (mentioned in the Figure 9 caption) are equal. All distances are in $\AA$ units, energy in $\mathrm{cm}^{-1}$.

TABLE 4: Predicted Cd/RG ${ }^{1} \mathbf{P}_{1} \leftarrow{ }^{1} S_{0}$ Absorption Wavelengths Obtained with Substitutional Site Occupancy ${ }^{a}$

\begin{tabular}{lcrcc}
\hline & $E^{\prime}(r=0)^{b}$ & $E^{\prime \prime}(r=0)^{b}$ & $\lambda_{\text {abs }}(\mathrm{nm})$ & $\lambda_{\text {obs }}(\mathrm{nm})$ \\
\hline $\mathrm{Cd} / \mathrm{Ne}$ & 49131.2 & 1774.6 & 211.16 & 220.2 \\
$\mathrm{Cd} / \mathrm{Ar}$ & 43670.0 & -421.8 & 226.80 & 221.0 \\
$\mathrm{Cd} / \mathrm{Kr}$ & 42103.4 & -1434.2 & 229.69 & 226.8 \\
$\mathrm{Cd} / \mathrm{Xe}$ & 39804.6 & -2536.1 & 236.18 & 235.6
\end{tabular}

${ }^{a}$ The observed absorption wavelengths are shown for comparison ${ }^{b}$ Energy units used are wavenumbers, $\mathrm{cm}^{-1}$.

TABLE 5: Predicted ${ }^{1} \mathbf{P}_{1} \rightarrow{ }^{1} S_{0}$ Emission Wavelengths in Nanometers for Body and Waist Modes of the Cd/Ar and $\mathrm{Cd} / \mathrm{Kr}$ Systems $^{a}$

\begin{tabular}{cccc}
\hline & observed & waist mode & body mode \\
\hline $\mathrm{Cd} / \mathrm{Ar}$ & 233.5 & 241.5 & \\
$\mathrm{Cd} / \mathrm{Kr}$ & $241.5,262.0$ & 273.2 & 315.3
\end{tabular}

${ }^{a}$ The observed experimental emission is also shown for comparison, no body mode emission was observed for Cd/Ar.

with fixed angles $\theta_{1}$ and $\theta_{3}$ from the $\mathrm{Cd}$ atom. Another contribution to be included is the interaction between the $\mathrm{Cd}$ atom and the four next-nearest neighbors (S.site2), which depends on the fixed variables $R_{4}$ and $\theta_{4}$. The lattice changes produced by this waist mode motion can be viewed in Figure 13 , which shows a "side on" view of the lattice $X Y$ plane. As the four nearest rare gas atoms from S.site1 contract, one can see these rare gas atoms detach themselves from the rare gas atoms they were bonded to on the diagonal, but in the process, they form four new rare gas - rare gas bonds with each other in a square plane. ${ }^{16}$ Thus, only a small destabilization of the lattice results from the waist mode as the breaking and forming of four rare gas bonds cancel out each other. Figure 14 depicts the ${ }^{1} \mathrm{~T}_{1 \mathrm{u}}$ electronic energy curves for the $\mathrm{Cd} / \mathrm{RG}$ systems and lists important waist mode values, for both the ground and excited states.

$\mathrm{Cd} / \mathrm{Ne}$ shows no stabilization for the waist mode calculation, a result also found in the body mode calculation. For $\mathrm{Cd} / \mathrm{Ar}$, $\mathrm{Cd} / \mathrm{Kr}$, and $\mathrm{Cd} / \mathrm{Xe}$ excited-state stabilization occurs, the contrac-

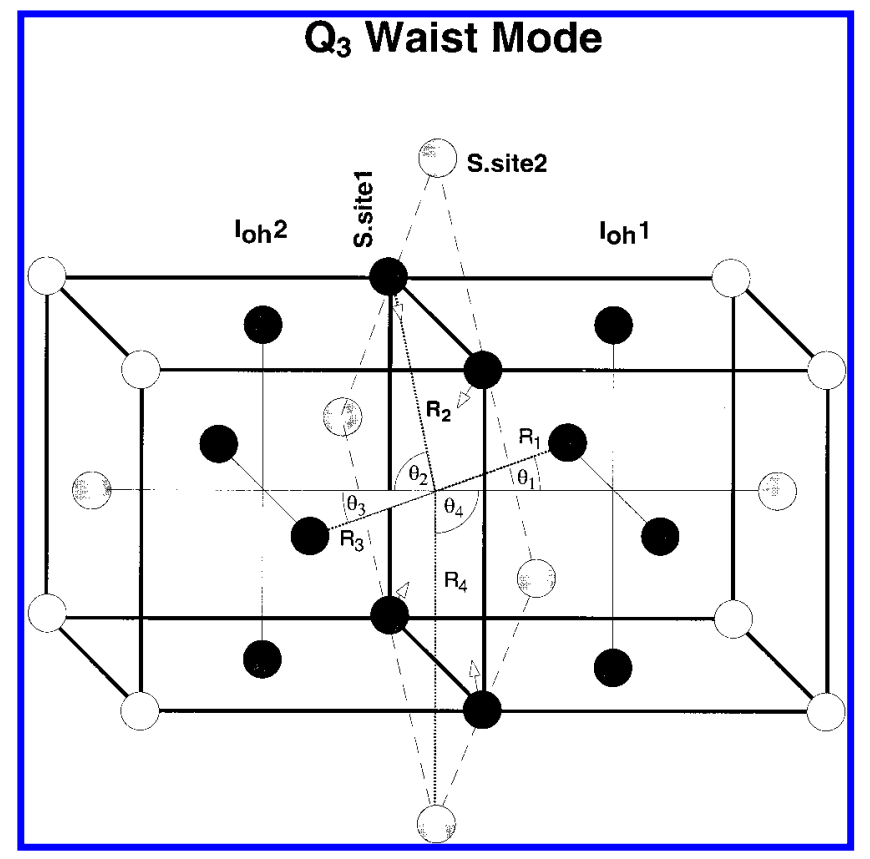

Figure 12. Angles and distance parameters utilized in the calculation of the "waist mode" $\left(\mathrm{Q}_{3}\right)$ motion. The four $\mathrm{Kr}$ atoms from S.site1 contract in-phase toward the $\mathrm{Cd}$ atom in the $X Y$ plane. Waist mode calculations also involve the fixed contributions: $\mathrm{I}_{\mathrm{oh}} 1+\mathrm{I}_{\mathrm{oh}} 2$ and that from S.site2.

tions of the respective rare gases (S.site1) are $0.47,0.82$, and $1.07 \AA$ as listed in Figure 14. The stabilization energy also increases as the rare gas atom size gets bigger. The calculated singlet absorption wavelengths are given in Table 4. These values are identical to those derived from body mode because they are both calculated at $R=0$, corresponding to zero displacement from the substitutional site.

\section{Discussion}

Table 6 shows a comparison between the number of observed and predicted ${ }^{1} \mathrm{P}_{1} \rightarrow{ }^{1} \mathrm{~S}_{0}$ emission bands for the four $\mathrm{Cd} / \mathrm{RG}$ 


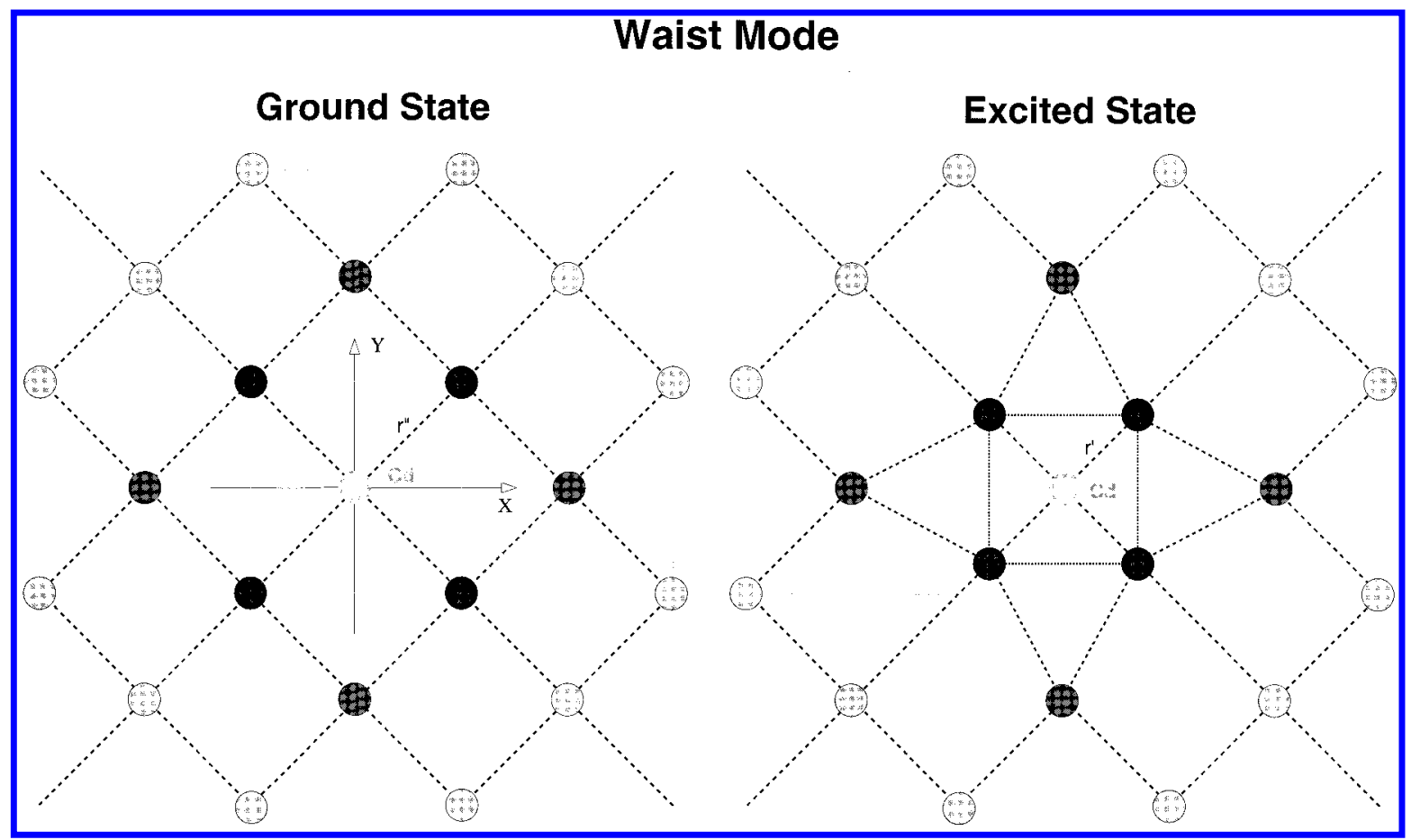

Figure 13. "Side-on" view through the adjoining unit cells of both the ground and excited states involved with the "waist mode". In the excited state, the four $\mathrm{Kr}$ atoms contract in the $X Y$ plane toward the $\mathrm{Cd}$ atom, detaching themselves from four $\mathrm{Kr}$ atoms but also forming four new $\mathrm{Kr}-\mathrm{Kr}$ bonds in the process. These forces balance each other, but as the atoms contract, eight $\mathrm{Kr}-\mathrm{Kr}$ bonds are distorted. Thus, there is a small net destabilization of the lattice.

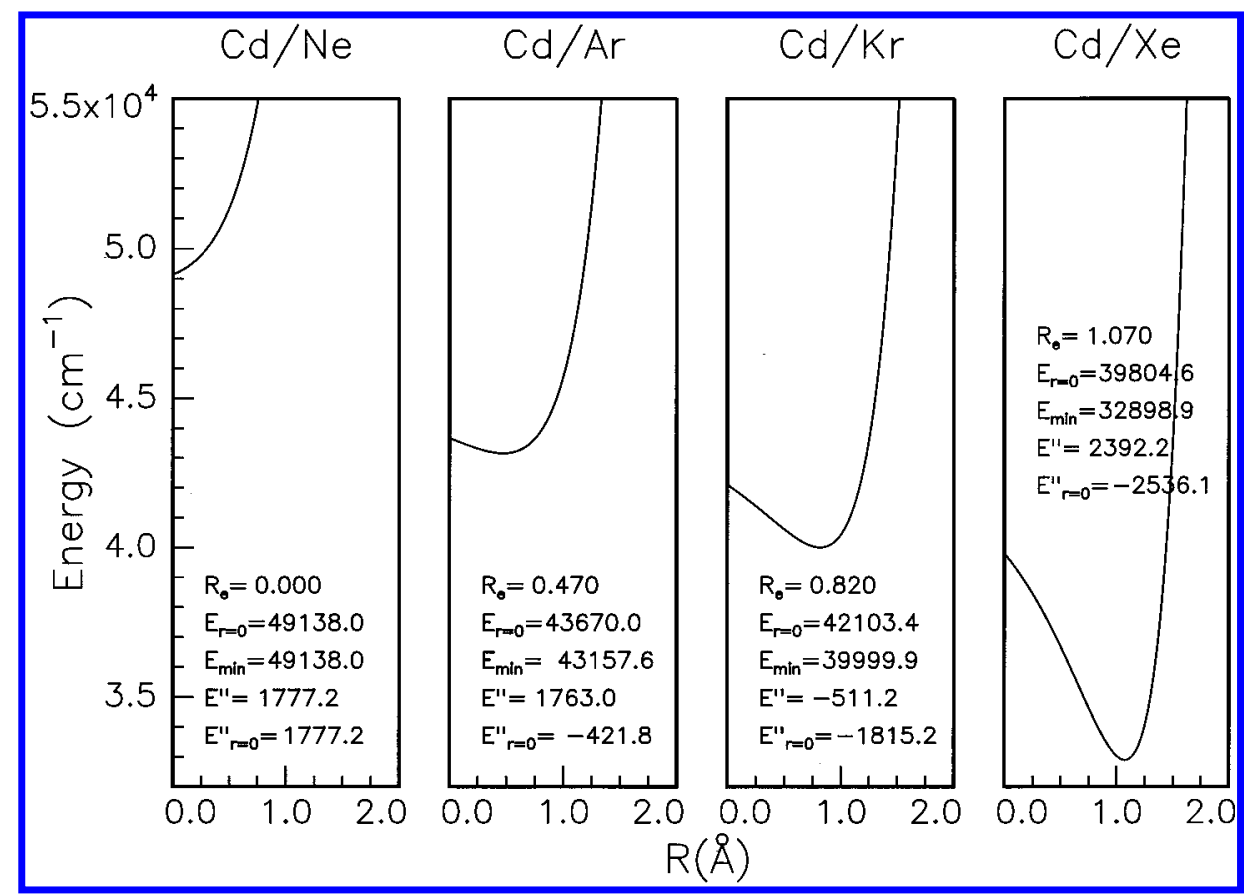

Figure 14. Potential energy plots for the vibronic "waist mode" in the $\mathrm{Cd} / \mathrm{RG}$ systems. Stabilization occurs for $\mathrm{Cd} / \mathrm{Ar}, \mathrm{Cd} / \mathrm{Kr}$, and $\mathrm{Cd} / \mathrm{Xe}$. As with the "body mode" plots, important ground-state parameters are listed. At $R_{\min }$, the destabilization of the lattice is equal to the stabilization induced by the in-phase contraction of the four $\mathrm{Kr}$ atoms toward the $\mathrm{Cd}$ atom. All distances are in $\AA$ units, energy in $\mathrm{cm}^{-1}$ units.

solids. Predictions for both $\mathrm{Cd} / \mathrm{Ar}$ and $\mathrm{Cd} / \mathrm{Kr}$ compare favorably with observation. In the $\mathrm{Cd} / \mathrm{Kr}$ system, two singlet emission bands are predicted in line with observation. The body and waist mode motions exist in this system and lead to distinct excitedstate energy minima from which two spectrally resolved emission bands occur. In all the $\mathrm{Cd} / \mathrm{RG}$ systems, with the exception of $\mathrm{Cd} / \mathrm{Ne}$, the waist mode leads to a lowering of energy. The existence of stabilization on the body mode in $\mathrm{Cd} /$ $\mathrm{Kr}$, corresponding to motion of the Cd atom from the substitutional site toward an adjacent octahedral interstitial site, is
TABLE 6: Comparison of the Number of Singlet Emission Bands Predicted with Those Observed for the Cd/RG Matrix Systems

\begin{tabular}{lll}
\hline & observed & predicted \\
\hline $\mathrm{Cd} / \mathrm{Ne}$ & one & none \\
$\mathrm{Cd} / \mathrm{Ar}$ & one & one \\
$\mathrm{Cd} / \mathrm{Kr}$ & two & two \\
$\mathrm{Cd} / \mathrm{Xe}$ & none ${ }^{a}$ & "two"
\end{tabular}

${ }^{a}$ Singlet emission is not observed in this system because of very efficient intersystem crossing. 
due to the favorable size matching between the bond length of the diatomic $\mathrm{Cd} \cdot \mathrm{Kr} \mathrm{C}{ }^{1} \Pi_{1}$ excited state $(3.17 \AA)$ and the distance of the $\mathrm{Kr}$ atoms to the center of the octahedral interstitial site $(2.82 \AA)$. In $\mathrm{Cd} / \mathrm{Ar}$ the bond length of the $\mathrm{C}^{1} \Pi_{1}$ state is 1.655 $\AA$ larger than the octahedral interstitial site, so repulsive interactions immediately set in, precluding stabilization of the body mode in the Ar lattice. This behavior is consistent with the single emission band recorded in the $\mathrm{Cd} / \mathrm{Ar}$ matrix system. $\mathrm{Cd} / \mathrm{Ar}$ shows stabilization only for the waist mode calculation, so this vibronic mode is identified as producing the recorded luminescence. The assumption inherent in the simulations, that a $\mathrm{Cd}$ atom will occupy a single substitutional site in $\mathrm{Ar}$ and $\mathrm{Kr}$ lattices, is thus plausible.

Correct prediction of the spectral position of the singlet emission energies has proved difficult for the $\mathrm{Cd} / \mathrm{Kr}$ system, as can be seen in Table 5. However, the trend exhibited in the excited-state stabilization energies, as illustrated in Figures 11 and 14 for the body and waist mode ${ }^{1} \mathrm{~T}_{1 \mathrm{u}}$ excited-state curves, is similar to those pertaining to the $\mathrm{Zn} / \mathrm{RG}$ matrix systems. The absorption wavelength calculated for $\mathrm{Cd} / \mathrm{Ar}$ showed a difference of $5.8 \mathrm{~nm}$ compared with its observed equivalent. The predicted values were obtained assuming the $\mathrm{Cd}$ atom occupies an undistorted substitutional site in the ground $\mathrm{X}^{1} \Sigma_{0}$ state. By viewing Table 6 , we can see that the substitutional site diameter of the Ar solid is $3.756 \AA$ whereas the $\mathrm{Cd} \cdot \mathrm{Ar}$ ground-state bond length is $4.31 \AA$, so the $\mathrm{Cd}$ atom is relatively cramped in a substitutional site of Ar. Given the 3-fold splitting clearly observed on the $\mathrm{Cd} / \mathrm{Ar}$ absorption band, ${ }^{4}$ which indicates JahnTeller coupling is occurring, it is likely that the $\mathrm{Cd}$ atom is residing in a highly symmetrical site in the ground state such as a substitutional site. ${ }^{17}$

Further calculations were done to identify the extent of expansion of the substitutional site of Ar with ground-state atomic cadmium occupancy. These involved equalization of the stabilization energy associated with allowing the 12 nearestneighbor Ar atoms to expand away from the $\mathrm{Cd}$ atom and the destabilization the motion of these argon atoms ${ }^{18}$ has on the lattice. The energies were obtained using eq 1 and the groundstate $\mathrm{Cd} \cdot \mathrm{Ar}$ and $\mathrm{Ar}_{2}$ potentials listed in Table 1. Calculation showed an expansion of $0.196 \AA$ in the substitutional site diameter with a resulting stabilization of $374.2 \mathrm{~cm}^{-1}$. When the excited-state calculations were rerun with the lattice parameter increased by $0.277 \AA(0.196 \times \sqrt{ } 2)$, an absorption wavelength of $225.3 \mathrm{~nm}$ was obtained, which compares better with the observed value at $222.2 \mathrm{~nm}$ than the $226.8 \mathrm{~nm}$ value obtained with the cramped substitutional site.

In $\mathrm{Cd} / \mathrm{Ne}$, a singlet emission band is not predicted even though a band is observed. The agreement between the predicted and observed wavelengths is poor in this system. As in the $\mathrm{Cd} /$ Ar system, the assumption of subtitutional site occupancy of $\mathrm{Cd}$ in $\mathrm{Ne}$ is the most likely reason for the discrepancy. The $\mathrm{Cd}$ atom will be severely cramped in a substitutional site of $\mathrm{Ne}$, which has a diameter of only $3.154 \AA$ compared to the bond length of $\mathrm{Cd} \cdot \mathrm{Ne}$ in the ground state, which is $4.26 \AA$. The absence of the 3-fold splitting in the excitation profile of $\mathrm{Cd} /$ $\mathrm{Ne}$ in Figure 1 and the poor comparisons between observed and predicted results suggest that the $\mathrm{Cd}$ atom does not occupy a substitutional site in the ground state but a multivacancy site.

Further calculations were performed to examine whether a tetravacancy is the site atomic $\mathrm{Cd}$ occupies in a neon matrix. These involved obtaining the extent of destabilization on the lattice by allowing the very cramped substitutional site of $\mathrm{Ne}$ to expand when occupied by a $\mathrm{Cd}$ atom. An increase of 0.324 $\AA$ in the substitutional site diameter was obtained in exactly the same manner as outlined above for $\mathrm{Cd} / \mathrm{Ar}$. The resulting lattice destabilization was found to be $402.8 \mathrm{~cm}^{-1}$. The energy of tetravacancy site occupancy was obtained by balancing the stabilization arising from the contraction of the 24 nearestneighbor $\mathrm{Ne}$ atoms surrounding the $\mathrm{Cd}$ atom and the $72 \mathrm{Ne}-$ $\mathrm{Ne}$ interactions changed with the $\mathrm{Cd}-\mathrm{Ne}$ contraction. The lattice destabilization energy was $233 \mathrm{~cm}^{-1}$, significantly less than the $402.8 \mathrm{~cm}^{-1}$ accompanying the expanded substitutional site occupancy, indicating the site occupancy to be tetravacancy.

Inspection of the body and waist mode plots for $\mathrm{Cd} / \mathrm{Xe}$ (Figures 11 and 14) shows that stabilization occurs for both modes in this system. Hence, two singlet emission features are predicted. This is not the case though because two triplet emission features are observed experimentally. ${ }^{4}$ The reason for the absence of singlet emission is attributed to intersystem crossing (ISC) from the excited singlet state ${ }^{1} \mathrm{~T}_{1 \mathrm{u}}$ to the metastable triplet ${ }^{3} \mathrm{~T}_{1 \mathrm{u}}$ state. This behavior is also exhibited in the diatomic $\mathrm{Cd} \cdot \mathrm{Xe}$ van der Waals complex. ${ }^{19}$ The mechanism proposed by Breckenridge for ISC in diatomic $\mathrm{Cd} \cdot \mathrm{Xe}$ is a crossing of the bound ${ }^{1} \Pi_{1}$ potential curve by the repulsive ${ }^{3} \Sigma^{+}$ state curve, leading to predissociation of the former state and production of triplet-state atomic cadmium. Excellent agreement exists between the observed and predicted $\mathrm{Cd} / \mathrm{Xe}$ absorption wavelengths, even though $\mathrm{Cd} \cdot \mathrm{Xe}$ possesses the strongest interactions of the $\mathrm{Cd} \cdot \mathrm{RG}$ systems. Table 3 shows that the larger the rare gas atom, the better the match between the substitutional site diameter and the $\mathrm{Cd} \cdot \mathrm{RG} \mathrm{X}{ }^{1} \Sigma_{0}$ bond length. Thus, of all the solid rare gases, atomic $\mathrm{Cd}$ fits most easily in the substitutional site of Xe.

\section{Conclusions}

Simulations carried out on the singlet luminescence of the $\mathrm{Cd} / \mathrm{RG}$ systems can be deemed a qualitative success because comparisons with observed and predicted singlet emission features worked well for $\mathrm{Cd} / \mathrm{Ar}$ and $\mathrm{Cd} / \mathrm{Kr}$. Predicted emission wavelengths though are not comparable to those observed possibly because of the highly repulsive nature, especially for $\mathrm{Cd} / \mathrm{Kr}$, of the ${ }^{1} \mathrm{~A}_{1 \mathrm{~g}}$ ground state. A reasonable argument is given for the discrepancy between the observed and predicted $\mathrm{Cd} / \mathrm{Ne}$ data. More work needs to be performed on the $\mathrm{Cd} / \mathrm{Ne}$ system, since spectral simulations must be carried out on $\mathrm{Cd}$ occupying the tetravacancy site predicted above as the more stable site.

The key conclusions to be gleaned from these calculations are the following. (1) Cd occupancy is in single substitutional sites of $\mathrm{Ar}, \mathrm{Kr}$, and $\mathrm{Xe}$ hosts with little or no distortion in the $\mathrm{Xe}$ lattice and considerable expansion of the surrounding spheres in Ar. Calculations based on single substitutional site occupancy of $\mathrm{Cd}$ in $\mathrm{Ne}$ are not consistent with observations. In neon a multivacancy site occupancy is expected from spectral observations and site occupancy calculations.

Singlet emission gives qualitative agreement between experiment and theory. In $\mathrm{Cd} / \mathrm{Ar}$, where a single emission band is observed, only the waist mode leads to excited-state stabilization. In $\mathrm{Cd} / \mathrm{Kr}$, which exhibits a pair of singlet emission bands, both waist and body modes lead to energy minima. The $\mathrm{Cd} / \mathrm{Ar}$ behavior contrasts with the $\mathrm{Zn} / \mathrm{Ar}$ (and $\mathrm{Zn} / \mathrm{Kr}$ ) for which pairs of minima were identified in line with observation. The difference between the $\mathrm{Zn} / \mathrm{Ar}$ and $\mathrm{Cd} / \mathrm{Ar}$ systems clearly originates from the larger size of the diatomic $\mathrm{Cd} \cdot \operatorname{Ar~} \mathrm{X}^{1} \Sigma_{1}$ and $\mathrm{C}^{1} \Pi_{1}$ states compared with the smaller values in diatomic $\mathrm{Zn}$. Ar. The longer bond length in the ground state of $\mathrm{Cd} \cdot \mathrm{Ar}$ means atomic cadmium is cramped in a substitutional site of Ar. Indeed, experiments show ${ }^{4}$ that upon deposition, a pair of sites exist in the $\mathrm{Cd} / \mathrm{Ar}$ matrix system, with removal of the thermally unstable "red" site never fully complete. 
Acknowledgment. The experimental portion of this research was funded by the European Union, TMR 1996-1998, “Access to Large Scale Facilities" Program (Grant No. ERBFMGECT 950059) and the Irish Government Forbairt Basic Science Research Scheme. B.H. also gratefully acknowledges Forbairt for receipt of a Ph.D. studentship.

\section{References and Notes}

(1) McCaffrey, J. G.; Ozin, G. A. J. Chem. Phvs. 1994, 101, 10354.

(2) Bracken, V. A.; Gürtler, P.; McCaffrey, J. G. J. Chem. Phvs. 1997, 107, 5290 .

(3) Crepin, C.; Tramer, A. J. Chem. Phvs. 1992, 97, 4772.

(4) Healy, B.; McCaffrey, J. G. J. Chem. Phvs. 1999, 110, 3903.

(5) McCaffrey, J. G.; Kerins, P. N. J. Chem. Phvs. 1997, 106, 7885.

(6) McCaffrey, J. G.; Healy, B. Unpublished results of 1999.

(7) Zuniga, J.; Bastida, A.; Requena, A.; Halberstadt, N.; Beswick, J. A. J. Chem. Phys. 1993, 98, 1007.

(8) Bastida, A.; Zuniga, J.; Requena, A.; Soep, B.; Halberstadt, N.; Beswick, J. J. Chim. Phys. (Paris) 1995, 92, 384

(9) Kerins, P.; McCaffrey, J. G. J. Chem. Phvs. 1998, 109, 3131.

(10) Funk, D. J.; Kvaran, A.; Breckenridge, W. H. J. Chem. Phvs. 1989, 90, 2915.

(11) Funk, D. J.; Breckenridge, W. H. J. Chem. Phvs. 1989, 90, 2927.

(12) The $A \mathrm{e}^{-b R}$ gives the potential energy curve a repulsive nature, where the $C_{6} / R^{6}$ provides an attractive portion to this curve.

(13) Kaup, J. G.; Breckenridge, W.H. J. Phvs. Chem. 1995, 99, 13701.

(14) Roncero, O.; Beswick, J.; Halberstadt, N.; Soep, B. Dynamics of Polyatomic van der Waals Complexes; Halberstadt, N., Janda, K., Eds.; Plenum Press: New York, 1990; p 471.

(15) Absorption to the ${ }^{1} \mathrm{~A}_{1}$ state of the $\mathrm{CdKr}_{4}$ cluster is predicted at $225.33 \mathrm{~nm}$, and emission from this state is predicted at $399.83 \mathrm{~nm}$. Hence, the absorption transition will be slightly to the blue of the atomic transition while a large red shift is expected in the emission.

(16) The "new bond formation" resulting from the excited-state waist mode is depicted in Figure 13. Thus, four new bonds are formed by the approaching four rare gas atoms when they have created the central square shown on the right of Figure 13, while four bonds on the axis of motion (the four diagonals) have been weakened. Examination of Figure 13 reveals that in the ground state the four atoms undergoing motion in the waist mode are not in direct contact; i.e., they are not at the equilibrium bond length of the rare gas dimer. They are in fact positioned at a distance of the lattice parameter, with a vacant octahedral interstitial site located between them. The extent of bond formation and bond breakage is nearly equal and just about cancels each other out in the waist mode. However, a much more minor extension of eight RG-RG interactions from equilibrium will always result in a energy increase, albeit small. The eight RG-RG interactions in question are the eight bonds connecting the contracting rare gas atoms (S.site1) and those from the next-nearest neighbors (S.site2) have been distorted, as depicted in the right panel of Figure 13, and are thus weakened.

(17) Hoffmann-Millack, B.; Klein, A.; Lagier, H.; Maid, B.; Hormes, J. J. Chem. Phvs. 1989, 136, 453.

(18) Outward motion of the 12 argon atoms surrounding the guest cadmium atom in a substitutional site results in a compression of the 12 $\mathrm{Ar}-\mathrm{Ar}$ distances directly on-axis and an expansion of the $24 \mathrm{Ar}-\mathrm{Ar}$ interactions existing on the surface of the first-sphere atoms. Because all the atoms undergoing motion are next-nearest neighbours, the $\mathrm{Ar}-\mathrm{Ar}$ expansions and contractions mentioned will be identical in magnitude with the extent of the $\mathrm{Cd}-\mathrm{Ar}$ expansion. The total number of $\mathrm{Ar}-\mathrm{Ar}$ interactions changing as a result of the substitutional site expansion is thereby 36.

(19) Bililign, S.; Gutowski, M.; Simons, J.; Breckenridge, W. H. J. Chem. Phvs. 1993, 99, 3815. 